\title{
Sacral sparing with cauda equina compression from central lumbar intervertebral disc prolapse*
}

\author{
DJ LAFUENTE, J ANDREW, A JOY \\ From the Residencia Sanitaria, Barcelona, Spain; The Middlesex Hospital, London, and Oldchurch Hospital, \\ Romford, $U K$.
}

SUMMARY Sparing of sensation in sacral dermatomes and of sphincter control was found in eight out of fourteen cases of severe cauda equina compression from massive central lumbar disc prolapse. Although the triangular shape of the lumbar spinal canal may be one factor for this it was found from a necropsy model that the increase in linear strain on the stretched roots of the cauda equina is least in the more centrally placed lower sacral roots. It is argued that the lower tension in these roots is determined by Young's Modulus.

It is well known in cases of spinal cord compression from intrinsic or extrinsic tumours, cutaneous sensibility may be preserved in the sacral dermatomes when it has been lost or impaired in the lumbar and thoracic territory below the segmental level of the lesion. This phenomenon has been ascribed to lamination of the dermatomes within the spinal cord, so that the sacral spinal pathways may be the least compressed, particularly from extrinsic lesions. The fact that the same phenomenon combined with sphincter preservation may occur with a large central lumbar disc prolapse causing cauda equina compression has passed largely unobserved. No reference to this feature could be found in the English or American literature, though some authors noted that the sensory loss was asymmetrical, incomplete or even absent. ${ }^{2}$ Paillas and his colleagues did observe sparing of sensation in sacral dermatomes in two out of six cases of severe cauda equina syndrome due to central lumbar disc prolapse, and believed that the explanation was the triangular shape of the lumbar spinal canal; they believed that the more centrally situated sacral nerves would be less compromised than the more laterally placed lumbar roots. ${ }^{3}$ (fig 1 ). A personally studied case prompted the further investigation of the phenomenon.

*Based on a paper read at a meeting of the Society of British Neurological Surgeons at Southampton in April 1983.

Address for reprint requests: Dr DJ Lafuente, Residencia Sanitaria Barcelona, Spain.

Received 17 August 1984 and in revised form 14 October 1984. Accepted 29 October 1984

\section{Case report}

A male, aged 42 years had six years previously suffered an episode of severe low back pain after heavy lifting which lasted several weeks; recovery was complete. Two weeks before his transfer from another hospital, he again lifted a very heavy object, and experienced excruciating back pain spreading to the front of both legs, and then he gradually lost the power in his lower limbs, so that after ten days he was unable to walk or stand; the front of his thighs, and of his legs below the knees felt numb. There was no difficulty in holding or passing urine although he was constipated. It was not possible to examine him standing because of pain and weakness. Straight leg raising was very limited and the femoral stretch test strongly positive. At the hips, the power was about MRC 4, both for flexion and extension; at the knees, for extension it was MRC 3 and flexion MRC 4; ankle and toe movements were between MRC 3 and 2 . There was gross blunting to pin prick in the front of the thighs below the second lumbar dermatome which extended down over the shins and lateral borders of the calves to the dorsum and outer borders of the feet. However, in the soles of the feet and the back of the calves, back of the thighs, buttocks and perianal area, cutaneous sensation was normal. The knee and ankle jerks were absent and the plantar responses flexor. Myelography showed a large central disc prolapse at the lumbar 2-3 level, beyond which very little contrast medium could pass. The disc prolapse was excised and recovery was complete.

Since 1968, sixty-eight cases of large central lumbar disc prolapse were treated in our departments, fourteen of these having a cauda equina syndrome (table). Of the total number, three were at the lumbar 2-3 level, six at lumbar 3-4, fifty at lumbar 4-5 and nine at the lumbo-sacral level. At both the lumbar 2-3 and 3-4 levels there were three cases with a severe cauda equina syndrome, but in only one case at each level was there saddle anaesthesia and sphincter loss. In three cases of central prolapse of the lumbar 


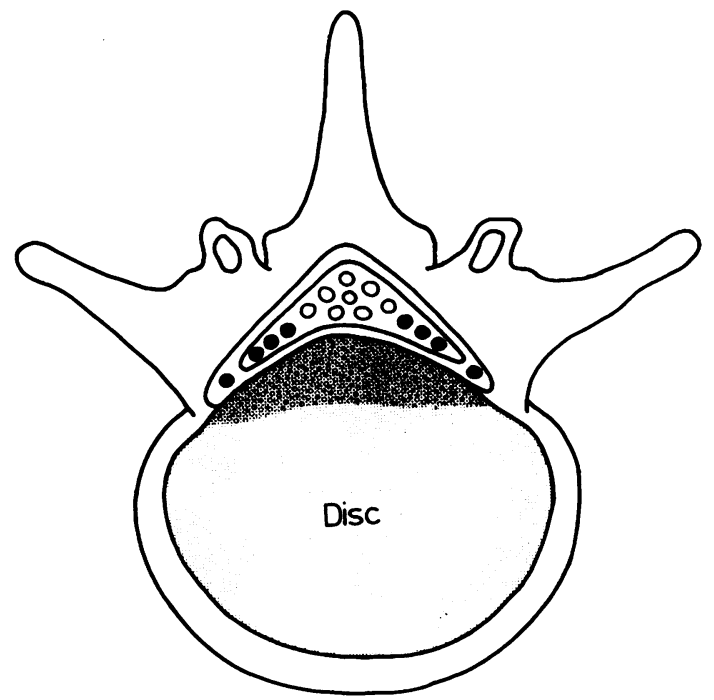

Fig 1 To illustrate that a massive central lumbar disc prolapse may compress or stretch the more laterally placed within the theca (after Paillas).

3-4 disc there were root symptoms only as occurs in the more common postero-lateral protrusion. The most frequent level for a central disc prolapse was the lumbar 4-5 where fifty were found, but in only five of these was there a severe cauda equina syndrome; sparing of the lower sacral dermatomes, S2, 3 and 4 occurred in four. The remaining forty-five patients only had back pain and root symptoms; this may be explained by the fact that the spinal canal at this level in more capacious and, there are fewer nerves to be compressed. However, at the last level (L5-Si) where there were three instances of cauda equina compression, there was a saddle anaesthesia and loss of sphincter control in each patient.

To explain the sacral sparing seen in some cases of central lumbar disc prolapse with a cauda equina syndrome, it seem that differences in the degree of tension created in the nerves within the theca might well account for the findings. To test the hypothesis laminectomies were performed in four cadavers. They extended from T9 to L5 and the roof of the sacral canal was also removed. The lumbar lordosis was obliterated to mimic the condition usually found in life in these cases. The dura was opened along the length of the exposure. The lumbar and sacral nerves were measured from their point of attachment to the cord above to the centre of each disc from L2-3 down and from the centre of each disc to the point of entrance of the nerve into its dural sheath below. An artificial disc prolapse was then made consecutively at each level from L2-3 and below, by placing bone wax to the height of about $8 \mathrm{~mm}$ across the posterior aspect of each disc in front of the theca. Each nerve was measured from the same points as before, but now stretched over the artificial disc protrusion. Increase in the length of each nerve above and below

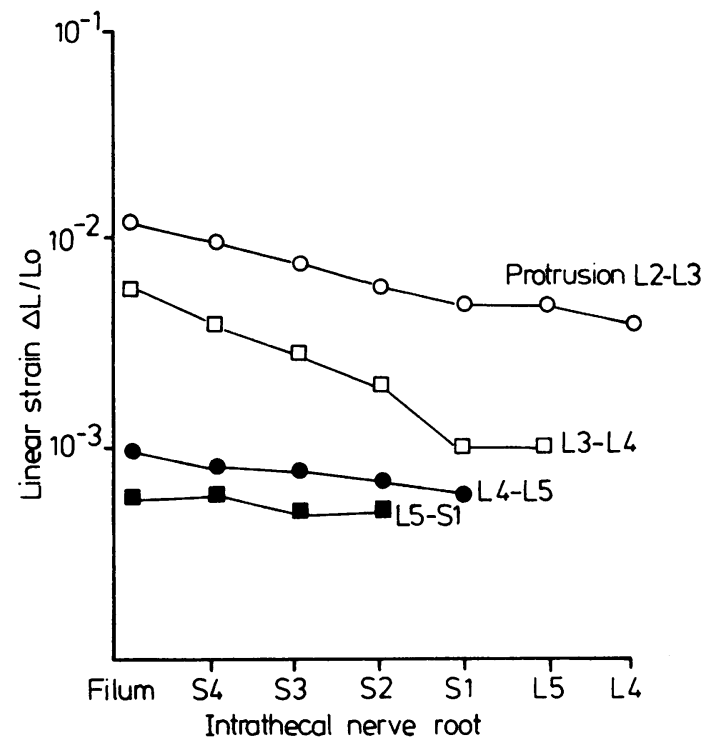

Fig 2 Strain as intrathecal nerve roots between cord attachment and summit of protrusion at each level from L2 $\checkmark$ S1.

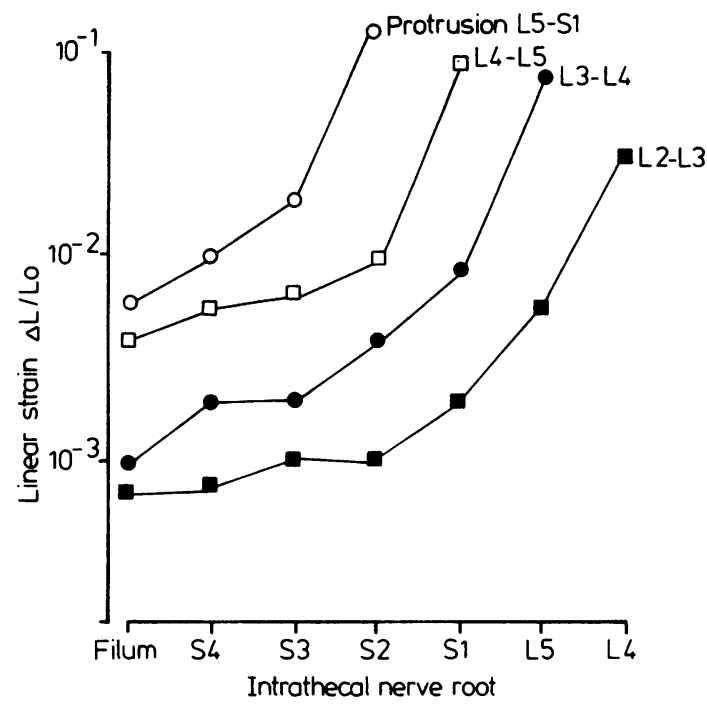

Fig 3 Strain on intrathecal nerve roots between summit of disc and dural sheath for each nerve, at levels from L2 - S1.

the protrusion due to stretching was recorded. These increases were smaller above the protrusion than below, and proportionally, were greater for the lumbar than for the sacral nerves. The apparent total increase in the length of any nerve was usually between $2-3 \mathrm{~mm}$.

Comparison of increases in lengths of nerves did not seem significant until they were related to the lengths of 
Table Clinical findings in cases of central lumbar disc prolapse

\begin{tabular}{lllll}
\hline $\begin{array}{l}\text { Level } \\
\text { Total number } \\
\text { at level }\end{array}$ & L 2-3 & L 3-4 & L 4-5 & L 5-S1 \\
\hline $\begin{array}{c}\text { Cauda equina syndrome } \\
\text { including saddle and } \\
\text { sphincter loss }\end{array}$ & 1 & 1 & 1 & 3 \\
$\begin{array}{c}\text { Cauda equina syndrome: } \\
\text { sacral and sphincter } \\
\text { sparing }\end{array}$ & 2 & 2 & 4 & 0 \\
$\begin{array}{c}\text { Back pain, unilateral or } \\
\text { bilateral radicular pain: } \\
\text { slight neurological signs }\end{array}$ & 0 & 3 & 45 & 6 \\
\hline
\end{tabular}

the unstretched nerves. If $\mathrm{L}_{0}$ is the length of an unstretched nerve between two points, and $L_{1}$ is the stretched length, the increase in length, $L_{1}-L_{0}$ may be expressed as $\Delta L$. This value $\Delta L$, was calculated for each level of protrusion, above and below the protrusion. The linear strain is calculated from the formula $\frac{\Delta L}{L_{0}}$ that is, the amount of stretch divided by the length of the unstretched nerve. This value was calculated for each nerve above and below each disc level where an artificial protrusion had been made. The linear strain in the nerves above the protrusion was found to be greater for the lower or sacral roots than for the upper or lumbar, due to the shorter distance to their attachment to the cord above (fig 2). More striking however, is the increased linear strain found in the nerves below the disc prolapse. The greatest increase is in the more laterally placed nerves, that is in the lumbar or upper sacral, below each protrusion. Because of the shorter lengths of nerve the strain will increase the lower the level of the protrusion. From a lumber 2-3 disc, the strain is greatest for the lumbar nerves and progressively lessens for the sacral, down to the filum. The strain is highest of all with a lumbo-sacral disc, at which level there was no sacral sparing in our cases (fig 3).

\section{Discussion}

To account for the spinal signs and limited straight leg raising or positive femoral nerve stretch test, O'Connell postulated that tension was created in extrathecal nerve roots stretched over the summit of a postero-lateral disc prolapse. ${ }^{4} \mathrm{We}$ believe that differences in tension between the roots of the cauda equina may offer an explanation for sacral sparing in cases of central lumbar disc prolapse. Tension or stress, which can be measured in terms of weight per unit area, could not be estimated in these experiments. Linear strain, however, could be measured in the manner described. $\frac{\text { Stress }}{\text { Linear strain }}$ is constant for all materials until their elasticity has been overcome. The constant is known as Young's Modulus. When estimating increases in linear strain, increases in tension of the nerves of the cauda equina caused by central lumbar disc prolapse may be gauged. It is suggested that differences in tension between the nerves of the cauda equina created by a massive lumbar disc prolapse, provide an alternative explanation for sacral and sphincter sparing in these cases.

We thank Dr KGW Heathfield for drawing our attention to this phenomenon of sacral and sphincter sparing with massive central lumbar disc prolapse as in the case described and which he referred.

\section{References}

1 Jennett WB. A study of 25 cases of compression of the cauda equina by prolapsed intervertebral discs. $J$ Neurol Neurosurg Psychiatry 1956;19:109-16.

${ }^{2}$ Robinson RG. Massive protrusions of lumbar discs. Br J Surg 1956;52:858-65.

${ }^{3}$ Paillas JE, Louis R, Brille J. La hernie due troisieme disque lombaire, de l'algie crurale au syndrome de la queue de cheval. Marseille-Chirurgical, 1964;16 No 4:289-95.

${ }^{4} \mathrm{O}$ ' Connell JEA. The indications for and results of the excision of lumbar intervertebral disc protrusions; a review of 500 cases. Ann R Coll Surg Engl 1950; 6:403-12. 